\title{
Assinatura geológica e influência do uso e da ocupação do solo na geoquímica de águas e sedimentos da bacia do ribeirão Caraça, Catas Altas, MG
}

Milene Aparecida Monteiro Mendes Mariangela Garcia Praça Leite Jorge Carvaho de Lena*

Universidade Federal de Ouro Preto (UFOP) Ouro Preto (MG), Brasil.

*Autor correspondente: jorge.delena@degeo. ufop.br

\section{Resumo}

O presente trabalho foi realizado na bacia hidrográfica do ribeirão Caraça, no município de Catas Altas, Minas Gerais. O objetivo principal foi obter parâmetros químicos e físico-químicos para caracterizar a geoquímica das águas e sedimentos desta bacia e determinar a real influência das atividades antropogênicas presentes na área. As nascentes do ribeirão Caraça se encontram em uma área de preservação ambiental (Parque Natural do Caraça), isenta de contaminação antrópica; porém, ao longo da bacia, existem diversos problemas de ordem ambiental, que podem ter origem na presença de áreas urbanas, atividades de mineração e agrícolas. Para este trabalho, foi realizado um estudo do uso e da ocupação do solo e monitorados 24 pontos, onde foram realizadas análises sazonais de água $(\mathrm{pH}, \mathrm{Eh}$, condutividade elétrica e oxigênio dissolvido) e medidos os teores de $\mathrm{SO}_{42}, \mathrm{Cl}^{-}$e $\mathrm{HCO}_{3}^{-}$(alcalinidade), além de metais (Al, Fe, Mn, Mg, Ca, K, Ti, P, As, Ba, Co, Cr, Cu, Ni, Sr, V, Zn e Zr, Na, $\mathrm{K}$, $\mathrm{Ca}$ e $\mathrm{Mg}$ ). Esses mesmos elementos foram determinados nas amostras de sedimentos. Os resultados permitiram dividir a bacia em três áreas distintas, com diferente ocupação e geoquímica. Apesar das atividades antropogênicas mostrarem grande influência sobre a geoquímica das águas, a composição dos sedimentos é influenciada fundamentalmente pela geologia local.

Palavras-chave: água, sedimento, Caraça.

\section{Abstract}

The present study was carried out in the Caraça stream basin, located at Catas Altas, Minas Gerais. The main goal was to obtain chemical and physical-chemical parameters in order to characterize the water and sediment geochemistry and ultimately to assess the real influence of the anthropogenic activities in the area. The springs are located in an environmental protection area (Parque Natural do Caraça), which is free from anthropogenic influence. However, in the basin area there are several environmental problems which may be caused by urban areas, mining activities and farms. For this study, a land use and occupation assesment was carried out and 24 sampling stations were monitored, where seasonal water analyzes were carried out for $p H, E h$, electrical conductivity and dissolved oxygen, concentrations of $\mathrm{SO}_{42}, \mathrm{Cl}$ and $\mathrm{HCO}_{3}^{-}$(alkalinity) in addition to metals ( $\mathrm{Al}, \mathrm{Fe}, \mathrm{Mn}, \mathrm{Mg}, \mathrm{Ca}, \mathrm{K}, \mathrm{Ti}, \mathrm{P}, \mathrm{As}, \mathrm{Ba}$, 
$\mathrm{Co}, \mathrm{Cr}, \mathrm{Cu}, \mathrm{Ni}, \mathrm{Sr}, \mathrm{V}, \mathrm{Zn}$ e $\mathrm{Zr}, \mathrm{Na}, \mathrm{K}, \mathrm{Ca}$ and $\mathrm{Mg}$ ). These same elements were also determined in sediment samples together with Si. The results allowed the division of the basin in three distinct areas according to occupation and geochemistry. The results show that the activities present in the basin have influence in that water quality, but the sediment composition is the reflex of only the local geology. Keywords: water, sediment, Caraça.

\section{INTRODUÇÃO}

A integridade de determinado trecho de um rio é reflexo das diversas influências sofridas pelo canal ao longo de seu curso (Bricker \& Jones 1995, Noori et al. 2010). É consenso o fato de que as concentrações dos elementos químicos em águas e sedimentos fluviais refletem os teores da rocha de origem, podendo ou não ser modificados por influência antrópica (Mitchell 1964, Pettry \& Switzer 1993; Vazhemin 1972, Négrel 2006, Tempel et al. 2000, Beaucaire \& Michard 1982, Lasaga 1984, Leite et al. 2006). O sucessivo crescimento econômico e populacional tem provocado um nítido aumento da demanda por recursos hídricos e minerais, intensificando os conflitos entre os diversos usos do solo e consequente degradação da qualidade desses ambientes aquáticos. Nesse sentido, as águas e os sedimentos possuem um valor inestimável para indicar mudanças nas condições ambientais dos ecossistemas fluviais, já que os vários processos que controlam a qualidade desse sistema fazem parte de um frágil equilíbrio, e mesmo pequenas alterações de ordem física, química ou climática podem modificá-la substancialmente.

As atividades antropogênicas, particularmente a explotação mineral, têm grande influência na integridade dos ecossistemas fluviais, especialmente nos ciclos geoquímicos dos metais (Li \& Zhang 2011). No entanto, como as variações espaciais e temporais desses elementos são, muitas vezes, difíceis de interpretar, um programa de mo- nitoramento que forneça uma estimativa representativa e confiável é indispensável para uma real avaliação dos processos de contaminação de uma determinada área (Dixon \& Chiswell 1996).

O estado de Minas Gerais representa um dos maiores potenciais minerários do País. Por consequiência, os problemas ambientais advindos da atividade extrativo-mineral na região são extremamente relevantes, dada a produção de rejeitos que leva, por vezes, lançamento de cargas de metais traço no sistema fluvial o que leva à contaminação de águas e sedimentos. $\mathrm{Na}$ atualidade, algumas pesquisas vêm tentando compreender a real dimensão desses impactos e buscar ações mitigadoras para os mesmos (Costa et al. 2010; Parra et al. 2007; Mendes 2007; Rhodes 2010).

Dentre as centenas de bacias existentes no Quadrilátero Ferrífero, a bacia do ribeirão Caraça possui características únicas que possibilitam o estudo e compreensão da influência de atividades antropogênicas em uma bacia hidrográfica. Porém, até o presente momento, não existem dados publicados sobre a real situação geoambiental de seus cursos de água. Assim, este trabalho visou estabelecer um programa de monitoramento de diversos parâmetros físico-químicos que possam ser utilizados em estudos futuros, permitindo embasar, por meio de dados geoquímicos, as condições da bacia do ribeirão Caraça, fornecendo base para o controle e monitoramento contra a degradação ambiental.

\section{1 Área de estudo}

O ribeirão Caraça está localizado no Estado de Minas Gerais, município de Catas Altas, distando cerca de $120 \mathrm{~km}$ da cidade de Belo Horizonte. O ribeirão começa a se formar no alto da serra do Caraça e se une ao rio Conceição, passando a se chamar rio Santa Bárbara, que, após se juntar ao rio Piracicaba, deságua, finalmente, no rio Doce. Suas nascentes se encontram em uma área preservada, isenta de contaminação antrópica, inseridas no Parque Natural do Caraça. Ao longo da bacia, existem diversos problemas de ordem ambiental, advindos do uso inadequado do solo, da expansão desordenada e das próprias limitações dos terrenos, destacando-se a influência das áreas urbanas, com desperdício dos recursos hídricos e contaminação dos mananciais, e as atividades minerárias, com explorações de ferro, ouro e serpentinito.

Em termos geológicos, a bacia situa-se na porção nordeste do chamado Quadrilátero Ferrífero (Almeida 1977, Almedia \& Hasui 1984, Dorr 1969). As unidades litoestratigráficas mais expressivas da área são o supergrupo Rio das Velhas e supergrupo Minas. O supergrupo Rio das Velhas, é dividido por Dorr et al. (1957), da base para o topo, nos grupos Nova Lima e Maquiné, ambos presentes na área estudada, sendo representados, principalmente, por formações ferríferas, metagrauvacas, metaconglomerados, rochas metavulcânicas, quartzitos sericíticos, xistos e filitos metassedimentares. O supergurpo Minas subdivide-se, da base para o topo, nos grupos Caraça, Itabira e Piracicaba (Alkmim 1987, Freitas et al. 1992, Rodrigues et al. 1993). O grupo Caraça, único aflorante na área em estudo, é constituído principalmente por quartzitos e xistos (Derby 1906). Já as coberturas sedimentares recentes presentes na bacia são: areia, argila, cascalho; solos lateríticos e concreções ferruginosas (Figura 1). 




Figura 1

Mapa geológico da área estudada.

\section{MATERIAIS E MÉTODOS}

A partir de um pluviômetro instalado pela Companhia Energética de Minas Gerais (CEMIG), em 1983, no Parque Natural do Caraça, foi possível fazer o estudo da precipitação para definição das estações de seca e chuva da bacia hidrográfica. Os dados foram levantados no banco de dados da Agência Nacional de Águas (Estação 02043059 - ANA, 2011).

Para o estudo do uso e ocupação da área, foi realizada a interpretação de dados de sensoriamento remoto (fotos aéreas nas escalas 1:60.000, USAF - Projeto 63-32, 1:20.000, FAB/IBGE - Projeto 1 -Área B, e 1:10.000, CEMIG dos anos 1966, 1974 e 1987, respectivamente, a imagem de satélite LANDSAT de 2000 e a imagem ASTER de 2008).

O estudo hidrogeoquímico se baseou em 24 amostras de água coletadas (Figura 2) entre os dias 23/09 e 28/10, correspondentes ao período de seca de 2005, e 23 amostras (o ponto MM07 não pode ser amostrado) entre os dias 02/03 e 18/03, correspondentes ao período chuvoso de 2006. A seleção dos pontos a serem amostrados foi feita em relação ao uso e à ocupação do solo. Para coleta e armazenamento das amostras de água, foram utilizados frascos de plástico (polietileno). Em cada ponto, coletaram-se duas amostras de água: uma em um frasco de $1 \mathrm{~L}$, para a análise de alcalinidade, cloreto e sulfato, e outra em frasco de $50 \mathrm{~mL}$, para análise de metais. Esta última foi filtrada com membrana $0,45 \mu \mathrm{m}$, acidificada com ácido nítrico até atingir o pH em torno de 2 e armazenada a $4^{\circ} \mathrm{C}$. $\mathrm{O} \mathrm{pH}$, Eh, a temperatura, a condutividade elétrica e os sólidos totais dissolvidos foram determinados in situ, utilizando-se um equipamento mul- 
tiparâmetro portátil ULTRAMETER TM 6P. O oxigênio dissolvido foi medido por um Oxímetro Handylab, modelo OXI 1/SET. Todos os equipamentos foram ajustados de acordo com instruções do fabricante e todas as determinações foram feitas com base nas metodologias propostas por Greenberg et al. (1992). As análises dos elementos maiores e traço foram efetuadas por meio de Espectrofotômetro de Emissão Óptica com Fonte Plasma (ICP OES), marca Spectro, modelo Ciros CCD com Visão Radial. As determinações de elementos traço em água foram validadas com uso de Material de Referência Certificado NIST 1604d, e nos sedimentos com NIST 2704.

No período de verão, foram coletadas, além das amostras de água, 18 amostras de sedimentos de corrente (Figura 2, pontos: MM01, MM03, MM06, MM09, MM10, MM12, MM13, MM14, MM15, MM16, MM17, MM18, MM19, MM20, MM21, MM22, MM23, MM24). Para a coleta das amostras de sedimentos, foram utilizados coletores de polietileno, sendo o material recolhido acondicionado em sacos plásticos de boca larga, que foram imediatamente selados e etiquetados após a coleta. As amostras de sedimentos foram então levadas para o laboratório e secas no interior de uma capela, sendo utilizadas lâmpadas de $200 \mathrm{~W}$ para manter o aquecimento em torno de $40^{\circ} \mathrm{C}$, a fim de evitar perda de elementos voláteis (Förstner 2004). Depois de secas, as amostras de sedimentos foram desagregadas, utilizando gral e pistilo, e separadas em duas frações granulométricas, uma $>2 \mathrm{~mm}$ e outra $<2 \mathrm{~mm}$. As amostras $<2 \mathrm{~mm}$ foram quarteadas e separadas em alíquotas que, posteriormente, foram utilizadas para análise de metais. As análises dos elementos traço foram efetuadas por meio de Espectrofotômetro de Emissão Atômica com Fonte Plasma (ICP OES), marca Spectro, modelo Ciros CCD com Visão Radial; uma massa de $0,2500 \mathrm{~g}$ de amostra foi solubilizada com ataque ácido $\left(\mathrm{HF}-\mathrm{HNO}_{3}-\mathrm{HClO}_{4}\right)$ e levada para um volume final de $25 \mathrm{~mL}$. A determinação dos elementos maiores ( $\mathrm{Si}, \mathrm{Al}, \mathrm{Fe}, \mathrm{Mn}, \mathrm{Ca}$, $\mathrm{K}, \mathrm{Mg}$ e $\mathrm{Ca}$ ) foi realizada por meio de Espectrômetro de Fluorescência de Raios-X, da Panalyitcal, modelo MagiX. Para o preparo das pastilhas, uma massa de $1,0000 \mathrm{~g}$ de amostra foi misturada com 3,0000 g de $\mathrm{Li}_{2} \mathrm{~B}_{4} \mathrm{O}_{7}$ e $3,0000 \mathrm{~g}$ de $\mathrm{LiBO}_{2}$. As determinações foram validadas com uso do Material de Referência Certificado GBW 7403.



Localização dos pontos de amostragem. 


\section{RESULTADOS E DISCUSSÃO}

A identificação dos padrões pluviométricos foi feita com o cálculo das precipitações médias mensais e a elaboração do hietograma, com as precipitações totais anuais (Estação 02043059 - ANA, 2011). Trata-se de uma região bastante chuvosa, com uma média da precipitação total anual de 1983,1 mm/ano, apresentando um ciclo básico unimodal bem definido, com verão chuvoso e inverno seco. O período chuvoso se estende de outubro a março e concentra $87,6 \%$ da pluviosidade anual; já o período seco, que vai de abril a setembro, concentra apenas $12,4 \%$. O período monitorado apresentou uma distribuição da precipitação semelhante às médias históricas.

O estudo do uso e da ocupação do solo possibilitou dividir a bacia do ribeirão Caraça em três áreas (Figura 3 ). A área 1 refere-se à parte mais a montante da bacia, onde está localizado o Parque Natural do Caraça. Os principais tributários da área 2, porção leste da bacia, são os córregos Brumadinho e Quebra Ossos, onde está localizada a mina Francisco III, que explora serpentinito. Já na área
3, porção oeste da bacia, existem dois tipos distintos de uso e ocupação do solo: no córrego do Engenho e no ribeirão Caraça, existem aglomerações urbanas e, no córrego Moinho de Olício, foi construída uma barragem que recebe os rejeitos sólidos e efluentes líquidos da mina de ouro Córrego do Sítio. O estudo geoquímico corrobora essa divisão, mostrando a influência direta da geologia, do uso e da ocupação na qualidade de águas e sedimentos da bacia.

De particular interesse são os teores de $\mathrm{Mn}$ e Fe nas águas. Nas duas estações, observa-se um valor excepcionalmente alto de Mn nos pontos MM20, MM21 e MM22 (4286, 2478 e $768 \mu \mathrm{g} / \mathrm{L}$ no verão e 4510, 1906 e $547 \mu \mathrm{g} / \mathrm{L}$ no inverno, respectivamente). Esses valores podem ser explicados pelos baixos valores de Eh das águas nesses pontos $(99,91$ e $123 \mathrm{mV}$ no verão e 58,61 e $58 \mathrm{mV}$ no inverno, respectivamente), o que favorece a liberação de metais. Observe-se que as amostras de sedimentos desses mesmos pontos apresentam valores altos de $\mathrm{MnO}(0,21$;
43'33'0'W 43'32'0'W 43'31'0'W 43'30'0'W 43'29'0'W 43'28'0'W 43'27'0'W 43'26'0'W 43'25'0'W

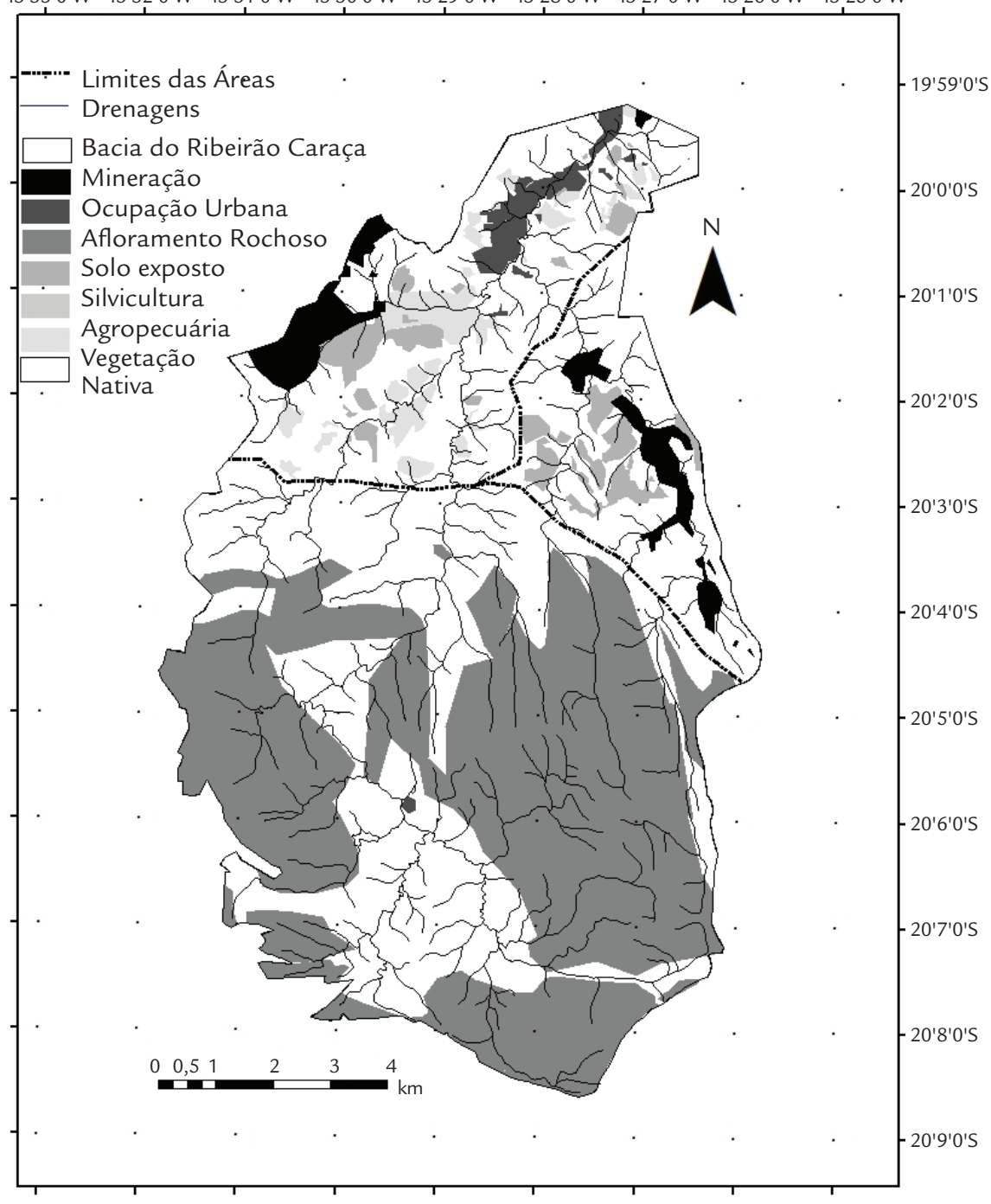

Figura 3

Divisão da bacia hidrográfica do ribeirão Caraça de acordo com o uso e ocupação do solo. 
$0,28$ e $0,28 \%)$. O ponto MM19 apresenta o maior valor de $\mathrm{MnO}$ em seu sedimento $(0,63 \%)$. No entanto, o valor mais alto de Eh $(163 \mathrm{mV})$ inibe a sua liberação para a água - nesse mesmo ponto, o valor de Mn é de $79 \mu \mathrm{g} / \mathrm{L}$. Essas condições caracterizam esse trecho da bacia como uma fonte de Mn para o sistema hídrico. A propagação efetiva desse elemento para a jusante da bacia é dificultada pelo aumento de Eh no ponto $14(193 \mathrm{mV})$, que apresenta um valor de $\mathrm{Mn}$ mais baixo em suas águas $(52 \mu \mathrm{g} / \mathrm{L}$ no verão e $93 \mu \mathrm{g} / \mathrm{L}$ no inverno). Essa mesma situação pode ser observada no trecho compreendido entre os pontos $15 \mathrm{e}$ 18. Ali, o baixo valor de Eh no ponto 17 (91 mV) favorece a liberação desse elemento $(146 \mu \mathrm{g} / \mathrm{L})$, cuja propagação se vê limitada logo no ponto 18 , com o aumento do valor de Eh $(187 \mathrm{mV})$, o que leva ao abaixamento do teor de $\mathrm{Mn}$ para $33 \mathrm{mV}$. Semelhante raciocínio pode ser delineado em relação ao Fe. Observe-se que, nesses mesmos pontos, valores mais baixos de Eh correspondem a valores mais altos de Fe nas águas (Tabela 1 ).

$\mathrm{Na}$ área 1, observam-se os menores valores de condutividade e alcalinidade (Tabela 1 e Figura 4), o que pode ser explicado pela ausência de atividades antropogênicas e pela geologia local, onde a principal rocha aflorante é o quartzito sericítico (Figura 3). Essa rocha é formada essencialmente por quartzo e pequenas quantidades de minerais que podem ser facilmente intemperizados, como as sericitas. No entanto, a quantidade de cátions liberada para a água como resultado da meteorização dessa rocha mostra-se pouco significativa, daí os baixos valores de condutividade e alcalinidade. Os mais altos valores desses parâmetros nas demais áreas, particularmente na área 3, são decorrentes da atividade mineradora ali praticada.

Nas três áreas e nas duas estações, Ca e $\mathrm{Mg}$ apresentam valores mais altos nas áreas 2 e 3 com reflexos nos valores de $\mathrm{CE}$; $\mathrm{Na}$ e $\mathrm{K}$ apresentam teores abaixo de $0,5 \mathrm{mg} / \mathrm{L}$. Os demais metais se encontravam abaixo do limite de detecção da técnica (As: $85 \mu \mathrm{g} / \mathrm{L}$; Ba: 0,5 $\mu \mathrm{g} / \mathrm{L}$; Co: $15 \mu \mathrm{g} / \mathrm{L}$; Cr :10 $\mu \mathrm{g} / \mathrm{L} ; \mathrm{Cu}: 2,5 \mu \mathrm{g} / \mathrm{L}$; Ni: $20 \mu \mathrm{g} / \mathrm{L}$; Sr: 0,5 $\mu \mathrm{g} / \mathrm{L} ; \mathrm{V}: 10 \mu \mathrm{g} / \mathrm{L}$; e Zn: 5,0 $\mathrm{Zg} / \mathrm{L})$. Sulfato foi

\section{CONCLUSÕES}

Em todos os cenários geológicos, as reações rocha-solo-água afetam a composição química de águas e sedimentos dos cursos de água localizados em uma determinada bacia hidrográfica, ou seja, litologias de naturezas distintas regulam os parâmetros físico-químicos, bem como a concentração dos diversos elementos químicos. Concomitantemente, a intensificação do uso múltiplo dos corpos aquosos acarreta alterações dessa assinatura original, sobretudo em córregos e rios localizados em áreas com intenso processo de urbanização e exploração mineral. A bacia do ribeirão Caraça reflete claramente a influência de atividades antropogênicas sobre a assinatura geológica na qualidade de águas e sedimentos de uma bacia hidrográfica.

Os resultados mostraram que as modalidades de uso determinado sempre abaixo de 2,0 $\mu \mathrm{g} / \mathrm{L}$, a turbidez abaixo de 10 FTU e o oxigênio dissolvido na faixa de 5,5 a 7,0 $\mu \mathrm{g} / \mathrm{L}$. Todos esses parâmetros foram observados em valores igualmente distribuídos nas três áreas e, aparentemente, não sofrem influência do uso e da ocupação do solo.

Com base nos dados hidrogeoquímicos obtidos, foi possível caracterizar as águas da bacia do ribeirão Caraça, em sua grande maioria, como sendo de classe I (Resolução CONAMA 357/05), que são águas destinadas ao abastecimento para consumo humano, com desinfecção; à preservação do equilíbrio natural das comunidades aquáticas; e à preservação dos ambientes aquáticos em unidades de conservação de proteção integral. Porém, as altas concentrações de Fe e Mn classificam as águas da área 3 como de classe IV, sendo inapropriadas ao contato humano.

Os sedimentos, por sua vez, apresentam uma relação mais direta com a geologia de cada área e refletem as atividades mineiras. A área 1, localizada sobre o grupo Caraça (Figura 1), apresenta, na composição de seu sedimento, teores de Si mais altos que as demais áreas (Tabela 2). Em contrapartida, nas áreas 2 e 3, que se encontram sobre os demais grupos litológicos (Figura 1), todos os demais valores foram claramente maiores, especialmente as concentrações de elementos traço, como Cr, Co, Ni e V (Tabela 2), característicos das rochas máficas e ultramáficas. Merece destaque a área 2, onde as concentrações desses elementos são bem maiores, especialmente do $\mathrm{Cr}$ e do Ni. Vale resaltar que é nessa região que se encontram, e são explotados, os serpentinitos do antigo grupo Quebra Ossos (Figura 1). É aí que se encontram os maiores teores de Fe e Mg. Os altos teores de alguns elementos calcófilos (As, $\mathrm{Cu}, \mathrm{Zn}$ e $\mathrm{Pb}$ ) nos pontos MM-19 e MM-20 (Figura 2), e naqueles que lhes estão a jusante do curso d'água (MM-22 MM-23 e MM-24 - Figura 2), provêm do córrego Moinho de Olício, que carreia sedimento proveniente da área de uma mineração de ouro (Figura 3), onde se encontram depósitos sulfetados.

E ocupação do solo têm influência direta na qualidade das águas da região, cuja composição é claramente modificada, especialmente onde são exercidas as atividades minerárias. Já os sedimentos refletem, por sua vez, em sua grande maioria, as características geoquímicas originais de cada área, apenas mostrando alterações significativas em pontos imediatamente a jusante da influência das minas.

Finalmente, este estudo demonstrou que monitoramentos em bacias hidrográficas, sistemáticos e estruturados, podem contribuir para um melhor entendimento dos ecossistemas fluviais, permitindo a quantificação da real contaminação de águas e sedimentos por atividades antropogênicas, ajudando no desenvolvimento de estratégias para o gerenciamento desses ecossistemas. 




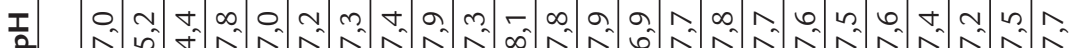

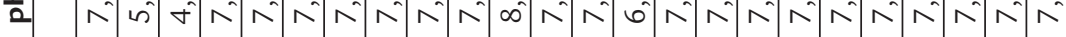

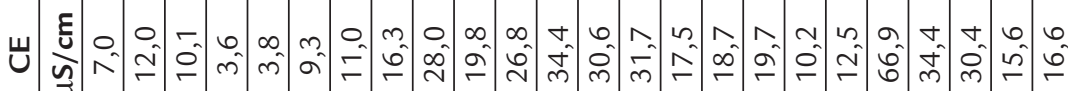

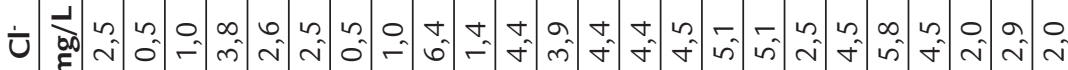

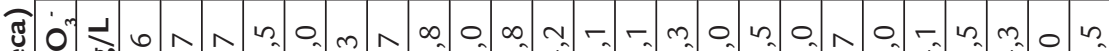

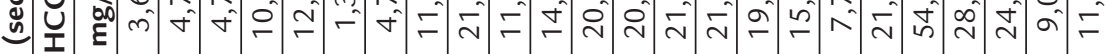

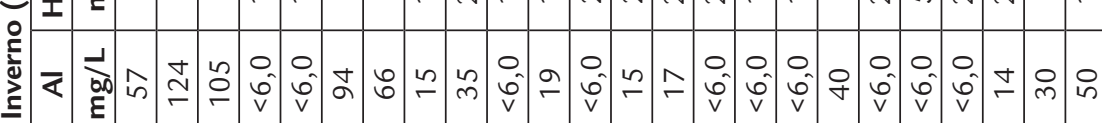

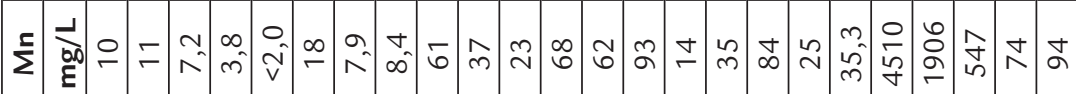

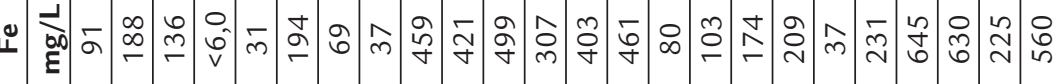

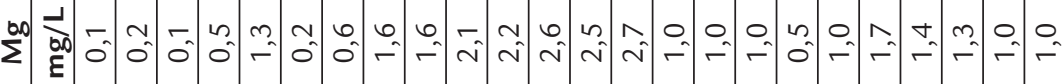
Uి Ш



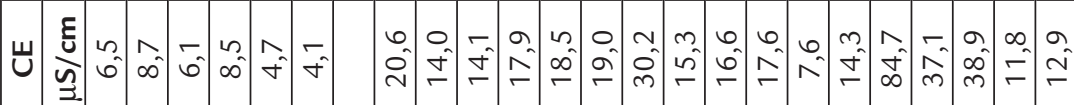

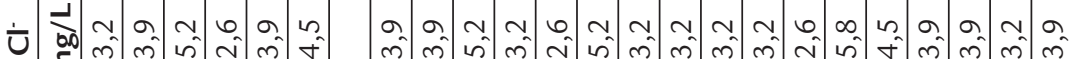
की

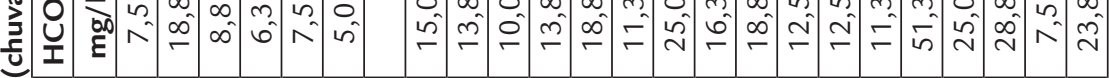









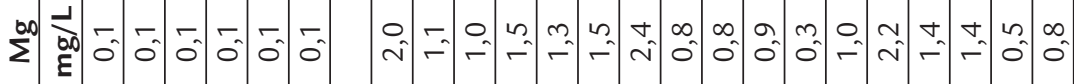


-

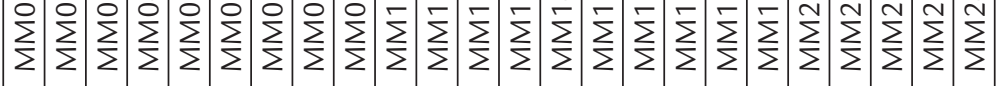



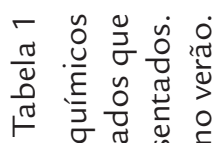

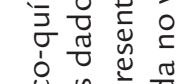

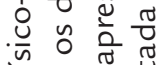
幽 n ก $\frac{\pi}{2}$ 空 选选 $\frac{\pi}{\frac{\pi}{2}}$

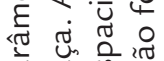
ส ล ก บ

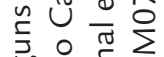

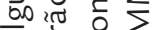
ฮ. तै

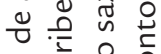
๑ 응 . त $\frac{\pi}{\pi} \cdot \frac{\pi}{\pi}$

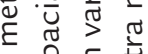
ก

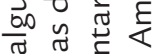
() ग ర ฆ त $\stackrel{-1}{1}$ 


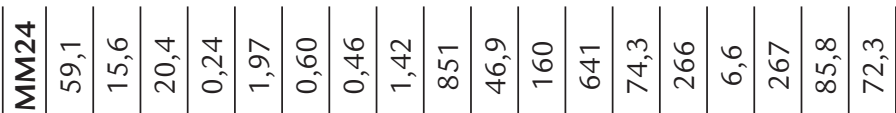

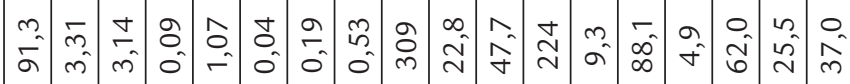

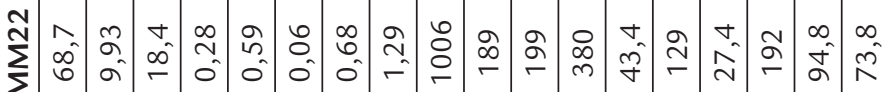

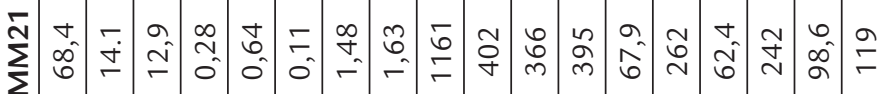

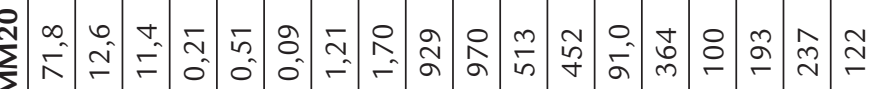

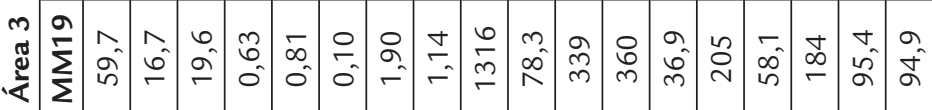

m

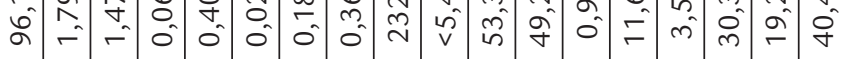

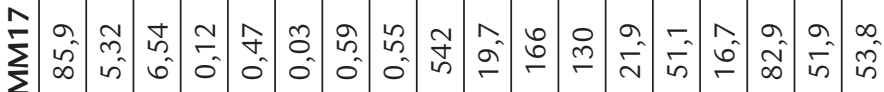

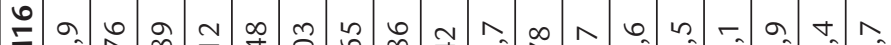

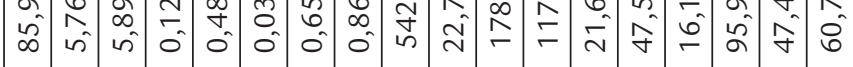



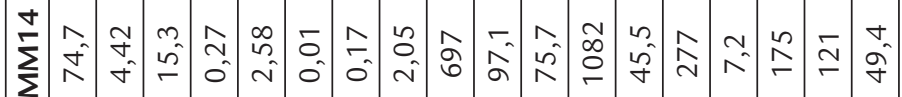

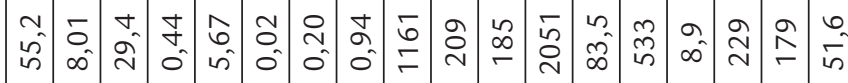

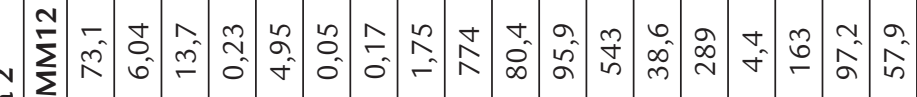

ฐึ

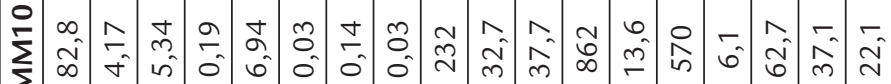

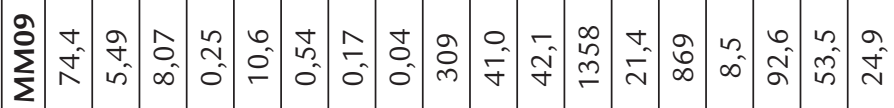

ஓ $\infty$ t

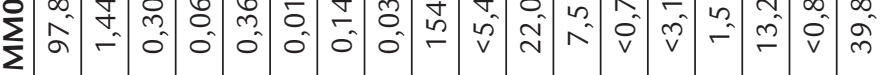

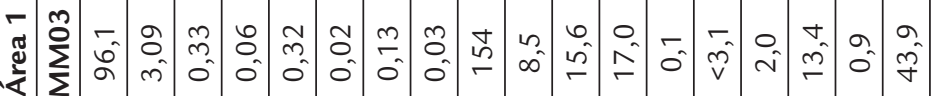

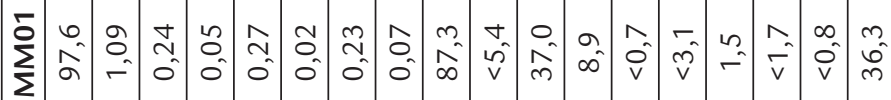

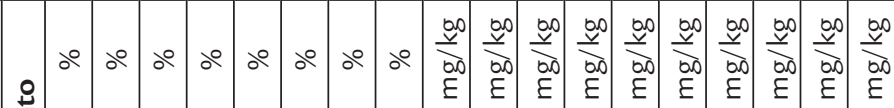

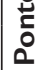

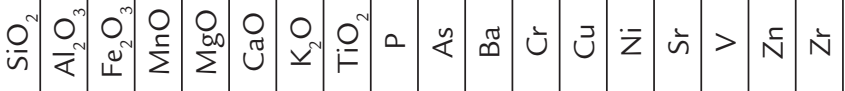




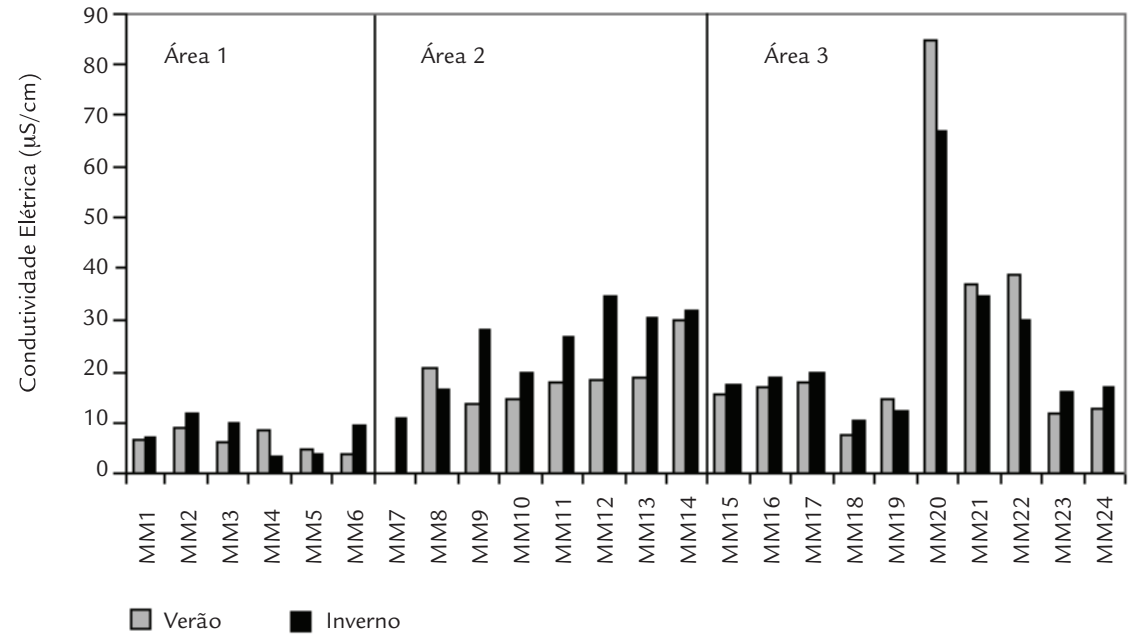

Área 1 - Parque Natural do Caraça.

Área 2 - Área com mineração de serpentinito.

Área 3 - Área com aglomerações urbanas e mineração de ouro.
Figura 4

Valores de Condutividade Elétrica para as amostras de águas nas duas campanhas de amostragem, destacando-se as divisões de área de acordo com o so e a ocupação do solo.

\section{AGRADECIMENTOS}

Os autores agradecem à CAPES pela bolsa de mestrado concedida à primeira autora; e ao Projeto de Cooperação Internacional CAPES/DAAD (415-br-probral/ale-02/21604) e ao Laboratório de Geoquímica Ambiental (LGqA) do Departamento de Geologia da Escola de Minas da UFOP pelo apoio logístico em todo o trabalho.

\section{REFERÊNCIAS}

Alkmim F.F. 1987. Modelo deposicional para a sequência dos metassedimentos da Serra de Ouro Branco, Quadrilátero Ferrífero, Minas Gerais. In: SBG, Simp. Sist. Depos. Pré-camb., Anais, p. 47-68.

Almeida F.F.M. \& Hasui Y.1984. O Pré-Cambriano do Brasil.E. Blücher, São Paulo.

Almeida F.F.M. O cráton do São Francisco. 1977. Revista Brasileira de Geociências, 7:349-364.

ANA (Agência Nacional de Águas). 2010. HidroWeb (Sistema de Informações Hidrológicas). Disponível em: http://hidroweb.ana.gov.br. Acessado em: 23 abr. 2008.

Beaucaire C. \& Michard G. 1982. Origin of dissolved minor elements (Li, $\mathrm{Rb}, \mathrm{Sr}, \mathrm{Ba}$ ) in superficial waters in a granitic area. Geochemical Journal, 16:247-258.

Bricker, O.P. \& Jones, B.F. 1995. Main factors affecting the composition of natural waters. In: B. Salbu \& E. Steinnes (eds.) Trace Elements in Natural Waters. CRC Press, Boca Raton FL, p. 1-5.

CONAMA (Conselho Nacional do Meio Ambiente). 2005. Resolução do CONAMA N 357 de 17 de março de 2005. Disponível em:http://www. mma.gov.br/port/ conama/res/res05/res375. Acessado em 3 jun. 2008.

Costa A.T., Nalini Jr H.A., Castro P.T.A., Tatumi S.H. 2010. Análise estratigráfica e distribuição do arsênio em depósitos sedimentares quaternários da porção sudeste do Quadrilátero Ferrífero, bacia do Ribeirão do Carmo, MG. Rem: Revista Escola de Minas, 63:701-714.

Derby O. A. 1906. The Serra do Espinhaço. The Journal of Geology, 14:374401.

Dixon W., \& Chiswell B. 1996. Review of aquatic monitoring program design. Water Research, 30:1935-1948.

Dorr II J.V.N. 1969. Physiographic, stratigraphic and structural development of the Quadrilatero Ferrifero, Minas Gerais, Brazil. Rio de Janeiro, DNPM/ USG. 
Dorr II J.V.N., Gair J. E., Pomerene J.B, Reynearson G. A. 1957. Revisão estratigrafica pré-cambriana do Quadrilátero Ferrífero. Trad. A.L.M. Barbosa. Rio de Janeiro, DNPM/DFPM.

Förstner U. 2004. Traceability of sediment analysis. Trends in Analytical Chemistry, 23:217-236.

Freitas M.E., Crocco R.F.A., Rosière C.A. 1992. Correlação do quartzito cambotas com a seqüência espinhaço apoiada por mapeamento geológico na escala 1:10.000. In: Simpósio de Geologia de Minas Gerais, 6, Revista da Escola da Minas, p. 51-53.

Greenberg A.E., Clesceri L.S., Eaton A.D. 1992. Standard methods for the examination of water and wastewater. American Public Health Association, Washington DC.

Lasaga A.C1984. Chemical kinetics of water-rock interaction. Journal of Geophysical Research, 89:4009-4025.

Leite M.G.P., Fujaco M.A.G., Nalini Jr H.A., Castro P.T.A. 2010. Influence of geology in the geochemistry signature of Itacolomi State Park waters, Minas Gerais-Brazil. Environmental Earth Sciences, 60:1723-1730.

Li S. \& Zhang Q. 2010. Spatial characterization of dissolved trace elements and heavy metals in the upper Han River (China) using multivariate statistical techniques. Journal of Hazardous Materials, 176:579-588.

Mendes M.A.M. 2007. Influência antrópica nas características hidrossedimentológicas e geoquímicas da bacia do ribeirão Caraça, Quadrilátero Ferrífero, MG. Dissertação de Mestrado, Universidade Federal de Ouro Preto, 94 p.

Mitchell R.L. 1964. Trace elements in soils. In: Bear F.E. (ed). Chemistry of the soil. Reinhold, New York, p. 320-368.

Négrel, P. 2006. Water granite interaction: clues from strontium, neodymium and rare earth elements in soil and waters. Applied Geochemistry, 21:1432-1454.

Noori R., Sabahi M.S., Karbassi A.R., Baghgvand A., Taati Zadeh H. 2010. Multivariate statistical analysis of surface water quality based on correlations and variations in the data set. Desalination, 260:129-136.

Parra R.R., Roeser H.M.P., Leite M.G.P., Nalini Jr. H.A., Guimarães A.T.A., Pereira J.C., Friese K. 2007. Influência antrópica na geoquímica de água e sedimentos do rio Conceição, Quadrilátero Ferrífero, Minas Gerais - Brasil. Geochimica Brasiliensis, 21:36-49.

Pettry D.E. \& Switzer R.E. 1993. Heavy metal concentration in selected soils and parent materials in Mississippi. MSU, Meridian, 33 p. (Bulletin 998).

Rhodes V.P. 2010. Distribuição de mercúrio e arsênio nos sedimentos de área afetada por garimpo de ouro - rio Gualaxo do Norte - Mariana. Dissertação de Mestrado, Universidade Federal de Ouro Preto 93 p.

Rodrigues L.C., Chemale F.Jr., Jost H. 1993. O posicionamento estratigráfico dos quartzitos da Serra do Caraça. In: Simp. Geol. de Minas Gerais, 7, Boletim da Sociedade Brasileira de Geologia, Núcleo Minas Gerais, 12:34-38.

Tempel R.N., Shevenell L.A., Lechler P., Price J. 2000. Geochemical modeling approach to predicting arsenic concentrations in a mine pit lake. Applied Geochemistry, 15:475-492.

Vazhemin I.G. 1972. Chemical composition of natural waters in the Vyg river basin in relation to the soil of central Karelia. Soviet Soil Science, 4:90-101. 